\title{
Epidemiology and in-Depth Clinical and Biochemical Assessment of Cushing's Syndrome - A Population-Based Study
}

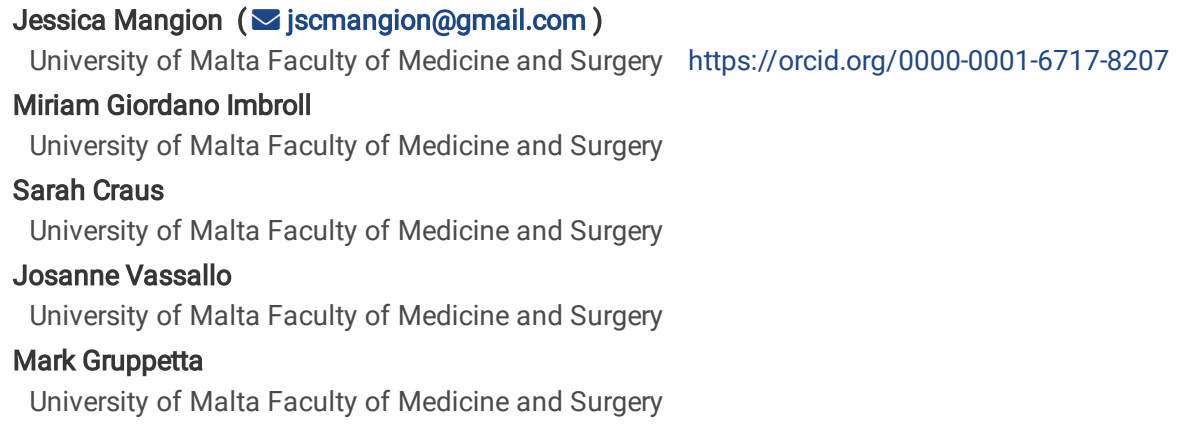

\section{Research Article}

Keywords: epidemiology, Cushing's Syndrome, incidence, neutrophil-lymphocyte ratio

Posted Date: November 10th, 2021

DOI: https://doi.org/10.21203/rs.3.rs-1055071/v1

License: @ (i) This work is licensed under a Creative Commons Attribution 4.0 International License. Read Full License 


\section{Abstract}

Purpose: To provide complete epidemiological data on Cushing's Syndrome (CS) with analysis and differentiation of biochemical parameters including blood count indices and serum inflammation-based scores.

Methods: Clinical records of 35 patients diagnosed with CS between 2008 and 2020 at the only central national health service hospital in Malta, were retrospectively analysed. Detailed clinical and biochemical data were obtained for each patient. Correlation and receiver operator characteristics (ROC) curve analyses were used to establish a threshold value for different variables to predict malignant CS.

Results: Standardized incidence rate (SIR) (/million/year) of CS was 4.5, SIR of Cushing's disease (CD) was 2.3, 0.5 for ectopic CS, 1.5 for cortisol secreting adrenal adenoma and 0.3 cases for cortisol-producing ACC. Malignant cause of CS had a statistically significant higher cortisol, size of tumour and lower potassium at diagnosis $(P<0.001)$. Additionally, malignant causes had a higher neutrophil-to-lymphocyte ratio (NLR) $(P=0.001)$, systemic immune inflammation index $(P=0.005)$ and a lower lymphocyte-to-monocyte ratio $(P<0.001)$. Using ROC curve analysis to predict malignant cause of CS, a potassium level of $<3.05$ was $75 \%$ sensitive and $100 \%$ specific (ROC-AUC $0.907, P=0.001$ ), a post-ODST cortisol level of $>841 \mathrm{nmol} / \mathrm{L}$ was $100 \%$ sensitive and $91 \%$ specific (ROC-AUC 0.981, $P<0.001$ ), while a NLR ratio $>3.9$ was $100 \%$ sensitive and $57.7 \%$ specific (ROC-AUC $0.885, P=0.001$ ).

Conclusion: Biochemical and blood count indices and serum inflammatory-based scores remarkably differ between benign and malignant causes of endogenous CS and such indices can help in predicting severity of disease and thus prognosis.

\section{Introduction}

Cushing's Syndrome (CS) is a rare but serious endocrine disorder characterised by persistent and inappropriate exposure to excessive concentrations of circulating glucocorticoids due to adrenocorticotropic hormone (ACTH)-dependent or non-ACTH dependent causes. Chronic hypercortisolaemia is associated with multiple comorbidities, with studies showing an association of CS with elevated morbidity and mortality rates $[1,2]$.

Despite CS being a serious condition, population-based epidemiological studies are limited [3] with incidence and prevalence data most commonly found for the commonest form of this condition, Cushing's disease (CD) [4-8]. Such studies enable the researcher to appropriately assess the disease burden and stratify disease severity and utilisation of health care resources [9].

Glucocorticoids play a significant role in inflammation and immune system disruption [10]. In fact, over the past years, there has been extensive research on the role of different blood components and serum inflammation-based scores on the prognosis of different cancers including patients with CD [11-13].

The purpose of this study was to investigate the national epidemiology of CS in Malta by carrying out a population-based study between 2008 and 2020 . We analysed different biochemical and blood count indices and serum inflammation-based scores in patients with all causes of endogenous CS and interpreted them in the context of available literature on $\mathrm{CD}$ and solid tumours. To our knowledge, analysis of such indices in a cohort of patients incorporating all causes of endogenous CS has not been reported yet.

\section{Methods}

Clinical records of 35 patients diagnosed with CS at the only central national health service (NHS) hospital in Malta, were retrospectively analysed. To ensure a complete data collection, subjects were identified from various databases including the outpatient medical and endocrine clinic records, surgical registries and operation notes as well as the Radiology Department registry. This multi-method data acquisition allowed for data triangulation. The population of Malta varied between 413609 and 516100 inhabitants at the start (2008) and the end (31st December 2020) of the study respectively [14].

Diagnosis of CS was confirmed by an endocrine specialist in accordance to the Endocrine Society diagnostic criteria of CS [15], by evaluating clinical features, biochemical data, imaging and histopathological reports. Overt CS was confirmed by a serum cortisol level $>138 \mathrm{nmol} / \mathrm{L}$ post-overnight dexamethasone suppression test (ODST), and a high 24-hour urinary cortisol. Serum ACTH level helped to classify patients into those having ACTH-dependent CS, as supported by a high serum ACTH level, and ACTH-independent CS, as supported by a suppressed serum ACTH level. Dynamic gadolinium-enhanced MRI of the pituitary gland and/or CT Thorax, Abdomen and Pelvis helped to establish the source of excessive ACTH production, subsequently subclassifying patients into those with CD or ectopic ACTH. In patients with ACTH-independent CS, CT of the adrenal glands helped to subclassify them into those with a benign cortisol-secreting adenoma or an adrenocortical carcinoma (ACC). In patients who underwent surgery or biopsy, CS was consolidated by the histopathology report.

The year in which the first abnormal serum cortisol post-ODST $(>138 \mathrm{nmol} / \mathrm{L})$ and a high urinary free cortisol were detected, was considered as the time of diagnosis. Detailed clinical and biochemical data were obtained for each patient. The complete blood count (CBC) obtained at diagnosis and within 3 months post-operatively was retrospectively analysed. The following scores were calculated: neutrophil-lymphocyte ratio (NLR) by dividing the absolute neutrophil count by the absolute lymphocyte count; platelet-lymphocyte ratio (PLR) by dividing the absolute platelet count by the absolute lymphocyte count; lymphocyte-monocyte ratio (LMR) by dividing the absolute lymphocyte count by the absolute monocyte count, and systemic immune-inflammatory index (SII) by multiplying the absolute platelet count and NLR.

The study was approved by the ethics committee at the University of Malta.

\section{Statistical analysis}


Standardised incidence rates (SIR) together with standardised mortality ratios (SMR) and prevalence figures were calculated, standardising with the World Health Organization 2001 standard population using the direct method [16]. Confidence intervals (95\% Cl) were calculated using Wilson's method.

Kolmogorov-Smirnov test was carried out to determine whether data was normally distributed and consequently non-parametric assessments were used, including spearman's correlation of the different variables. Results were expressed as medians since data was not normally distributed. Receiver operator characteristics (ROC) curve analyses were used to obtain a threshold value for a particular variable predicting a certain outcome. Statistical analyses were carried out using IBM SPSS ${ }^{\circledR}$ Statistics for Windows, Version 27.0 (IBM Corp. Armonk, NY, USA). Two-sided $P$ values below 0.05 were considered as statistically significant.

\section{Results}

Thirty-five patients were diagnosed with endogenous Cushing's syndrome between 2008 and 2020, 21 of which were ACTH-dependent and 14 were ACTHindependent.

\section{Incidence and Prevalence}

Over the 12-year study period, the total incidence of endogenous CS was 4.5 cases per million/year with female predominance. The incidence of CD was 2.3 cases per million/year, 0.5 cases per million/year for ectopic CS, 1.5 cases per million/year for cortisol secreting adrenal adenoma and 0.3 cases per million/year for cortisol-producing ACC. Ectopic CS had a strong male predominance, with a SIR of 1.0 case per million per year, whilst ACTH-independent CS had a strong female predominance, with a SIR of 3.2 cases per million/year. Further details are shown in Table 1. With regards to prevalence, at the end of the study period (end of 2020) 33 patients were identified to have had endogenous Cushing's syndrome and are still alive. Hence, the calculated overall prevalence was 63.9 per million population (Table 1 ).

Table 1

Prevalence, Incidence and further epidemiological characteristics of Cushing's syndrome patients and subtypes

\begin{tabular}{|c|c|c|c|c|c|c|}
\hline & \multirow{2}{*}{$\begin{array}{l}\text { All Cushing's } \\
\text { Syndrome }\end{array}$} & \multicolumn{2}{|c|}{ ACTH Dependent } & \multicolumn{3}{|c|}{ ACTH Independent } \\
\hline & & $\begin{array}{l}\text { Cushing's } \\
\text { Disease }\end{array}$ & $\begin{array}{l}\text { Ectopic ACTH } \\
\text { Secretion }\end{array}$ & ACC & $\begin{array}{l}\text { Cortisol Secreting Adrenal } \\
\text { Adenoma }\end{array}$ & $\begin{array}{l}\mathrm{P} \text { - } \\
\text { Value }\end{array}$ \\
\hline \multicolumn{7}{|l|}{ Incidence Estimates (2008-2020) } \\
\hline Number of patients (n) & 35 & 16 & 5 & 3 & 11 & \\
\hline $\begin{array}{l}\text { Overall SIR (/1,000,000/yr) (95\% } \\
\text { Cl) }\end{array}$ & $4.5(3.1-6.6)$ & $2.3(1.4-3.9)$ & $0.5(0.2-1.5)$ & $0.3(0.1-1.2)$ & $1.5(0.8-2.8)$ & \\
\hline Male (n) (\%) & $14(40.0)$ & $8(50.0)$ & $5(100.0)$ & $0(0)$ & $1(9.0)$ & \multirow[t]{2}{*}{0.002} \\
\hline Female (n) (\%) & $21(60.0)$ & $8(50.0)$ & $0(0.0)$ & $3(100.0)$ & $10(91.0)$ & \\
\hline SIR male $(/ 1,000,000 / y r)(95 \% \mathrm{Cl})$ & $3.5(1.9-6.4)$ & $2.2(1.0-4.7)$ & $1.0(0.3-2.9)$ & $0.0(0.0-1.3)$ & $0.3(0.1-1.9)$ & \\
\hline $\begin{array}{l}\text { SIR female }(/ 1,000,000 / y r)(95 \% \\
\text { Cl) }\end{array}$ & $5.6(3.5-9.1)$ & $2.4(1.2-5.0)$ & $0.0(0.0-1.3)$ & $0.6(0.1-2.4)$ & $2.6(1.3-5.3)$ & \\
\hline Passed away (n) (\%) & $9(25.7)$ & $2(12.5)$ & $5(100.0)$ & $2(66.7)$ & $0(0)$ & $<0.001$ \\
\hline $\begin{array}{l}\text { Standardised Mortality Ratio } \\
(\mathrm{SMR})(95 \% \mathrm{Cl})\end{array}$ & $2.8(1.0-4.6)$ & $1.1(0.0-2.7)$ & $6.9(1.8-12.1)$ & & & \\
\hline $\begin{array}{l}\text { Median longest diameter at } \\
\text { diagnosis (IQR) }\end{array}$ & $28(7.5-42.5)$ & $6(5.3-16.5)$ & $55(47.5-67.5)$ & $\begin{array}{l}103(81.5- \\
103.0)\end{array}$ & $30(27.0-35.0)$ & $<0.001$ \\
\hline Median Age at diagnosis (IQR) & $55(42.5-61.5)$ & $\begin{array}{l}45.5(39.5- \\
59.0)\end{array}$ & $62(61.0-66.0)$ & $\begin{array}{l}62(59.5- \\
64.0)\end{array}$ & $55(41.0-58.5)$ & \\
\hline \multicolumn{7}{|l|}{$\begin{array}{l}\text { Prevalence Estimates (31st } \\
\text { December 2020) }\end{array}$} \\
\hline Number of patients (n) & 33 & 20 & 0 & 2 & 11 & \\
\hline $\begin{array}{l}\text { Overall Prevalence }(/ 1,000,000) \\
(95 \% \mathrm{Cl})\end{array}$ & $63.9(45.5-89.8)$ & $\begin{array}{l}38.8(25.1- \\
59.9)\end{array}$ & $0.0(0.0-7.4)$ & $\begin{array}{l}3.9(1.1- \\
14.1)\end{array}$ & $21.3(11.9-38.2)$ & \\
\hline $\begin{array}{l}\text { Male Prevalence }(/ 1,000,000) \\
(95 \% \mathrm{Cl})\end{array}$ & $30.0(15.2-59.1)$ & $\begin{array}{l}26.2(12.7- \\
54.1)\end{array}$ & $0.0(0.0-14.4)$ & $\begin{array}{l}0.0(0.0- \\
14.4)\end{array}$ & $3.7(0.7-21.2)$ & \\
\hline $\begin{array}{l}\text { Female Prevalence }(/ 1,000,000) \\
(95 \% \mathrm{Cl})\end{array}$ & $\begin{array}{l}100.3(68.0- \\
148.1)\end{array}$ & $\begin{array}{l}52.2(30.5- \\
89.3)\end{array}$ & $0.0(0.0-15.4)$ & $\begin{array}{l}8.0(2.2- \\
29.3)\end{array}$ & $40.1(21.8-73.9)$ & \\
\hline Median Age at diagnosis (IQR) & $46(40.0-58.0)$ & $\begin{array}{l}44.5(38.0- \\
54.5)\end{array}$ & & $\begin{array}{l}61.5(59.3- \\
63.8)\end{array}$ & $55.0(41.0-58.5)$ & \\
\hline
\end{tabular}

\section{ACTH-Dependent Cushing's Syndrome}


Sixteen patients were diagnosed with CD, of which 8 (50.0\%) were females and 8 (50.0\%) were males (Table 1). Five (31.3\%) patients had a macroadenoma $(\geq 10 \mathrm{~mm})$, while $11(68.8 \%)$ patients had a microadenoma $(<10 \mathrm{~mm})$. All $(n=16)$ patients underwent transsphenoidal pituitary surgery, $12(80 \%)$ of whom were cured post-operatively. Six (37.5\%) patients had Diabetes Mellitus (DM) pre-operatively; 10 (62.5\%) patients had hypertension (HT). Only 2 (12.5\%) patients passed away within the 12-year follow-up period (Table 1).

Throughout the study period, five patients were diagnosed with ectopic CS aged 55, 61, 62, 66 and 75 respectively. One patient had an ACTH-secreting gastric mixed neuroendocrine-non-neuroendocrine neoplasm (MiNEN), another patient had ACTH-positive neuroendocrine pancreatic tumour and another patient had small cell lung carcinoma. On the other hand, one had a metastatic neuroendocrine carcinoma with an unknown primary whilst one patient had an unidentified ectopic ACTH secreting tumour. Three (60\%) patients had DM pre-operatively; $2(40 \%)$ had HT. All of the patients with ectopic CS were males and all had passed away during the 12-year follow-up period (Table 1). Details regarding their biochemical parameters are found in Table 2.

Table 2

Differences between different subtypes of endogenous Cushing's syndrome different subtypes - medians (IQR) and $p$-values

\begin{tabular}{|c|c|c|c|c|c|}
\hline & ACTH-secreting PA & $\begin{array}{l}\text { Benign cortisol-secreting } \\
\text { adenoma }\end{array}$ & Ectopic ACTH & ACC & $\begin{array}{l}p \text { - } \\
\text { value }\end{array}$ \\
\hline ACTH (pmol/L) & $100.0(53.5-140.5)$ & $5.0(1.3-8.0)$ & $242.0(227.8-278.5)$ & $0.0(0.0-0.0)$ & $<0.001$ \\
\hline ODST Cortisol (nmol/L) & $311.5(258.5-589.5)$ & $427.0(305.8-573.3)$ & $\begin{array}{l}2574.0(2439.3- \\
2741.8)\end{array}$ & $\begin{array}{l}1149.0(1029.5- \\
1315.5)\end{array}$ & 0.002 \\
\hline Baseline Cortisol (nmol/L) & $586.0(512.3-782.0)$ & $578.0(513.0-606.0)$ & $2025.0(2014-2512)$ & $1152.0(935-1180.5)$ & 0.001 \\
\hline $\mathrm{K}^{+}$at diagnosis (mmol/L) & $4.3(4.2-4.7)$ & $4.6(4.0-4.9)$ & $2.0(2.0-2.2)$ & $4.1(3.0-4.2)$ & 0.004 \\
\hline Size of Tumour (mm) & $6.0(5.5-15)$ & $30.0(27-35)$ & $55.0(47.5-67.5)$ & $103.0(81.5-103)$ & $<0.001$ \\
\hline $\begin{array}{l}\text { 24hr Urinary Cortisol } \\
\text { (nmol/24hrs) }\end{array}$ & $\begin{array}{l}1480.0(782.0- \\
2207.0)\end{array}$ & $1075.5(861.8-2217.0)$ & $3236.0(1380-4138)$ & $\begin{array}{l}5830.5(5242.3- \\
6418.8)\end{array}$ & 0.038 \\
\hline $\begin{array}{l}\text { Lymphocyte Count pre-Rx } \\
\left(\mathrm{x} 10^{9} / \mathrm{L}\right)\end{array}$ & $1.8(1.54-2.34)$ & $1.9(1.55-2.53)$ & $1.0(0.41-1.08)$ & $1.2(1.20-1.42)$ & 0.022 \\
\hline $\begin{array}{l}\text { Eosinophil Count pre-Rx } \\
\left(\mathrm{x} 10^{9} / \mathrm{L}\right)\end{array}$ & $0.081(0.02-0.14)$ & $0.05(0.04-0.09)$ & $0.0(0.00-0.01)$ & $0.04(0.04-0.07)$ & 0.014 \\
\hline Platelet Count $\left(\times 10^{9} / \mathrm{L}\right)$ & $308(273-351.5)$ & $276.5(263.5-285.5)$ & 184 (166.5-192.75) & $265(261-369)$ & 0.029 \\
\hline Neutrophil-to-Lymphocyte Ratio & $3.6(2.6-4.9)$ & $3.8(2.2-4.6)$ & $10.8(8.9-25.2)$ & $5.2(4.6-7.3)$ & 0.009 \\
\hline Lymphocyte-to-Monocyte Ratio & $2.5(2.1-2.9)$ & $2.5(2.2-2.8)$ & $1.4(0.9-1.6)$ & $2.0(1.8-2.1)$ & 0.009 \\
\hline
\end{tabular}

\section{ACTH-Independent Cushing's Syndrome}

Eleven patients were diagnosed with benign adrenal cortisol-secreting adenoma, of which only 1 (9\%) patient was a male. One patient ( $9 \%$ ) had DM preoperatively; 6 (54.5\%) patients had HT. None of these patients passed away during the 12-year follow-up period. Ten patients underwent adrenalectomy, whilst one patient was still awaiting surgery. All patients were cured post-operatively.

Three patients were diagnosed with an ACC, one of which was an ectopic ACC found in the retroperitoneum. All of the patients were females aged 57,62 and 66 years respectively. Two (66.6\%) patients had DM pre-operatively; no one had HT. Two of the patients passed away (Table 1). Details regarding their biochemical parameters are found in Table 2 .

\section{Comparisons Between Various Subtypes}

When comparing benign and malignant causes of CS, there were interesting statistically significant differences in a number of parameters including the cortisol post-ODST, potassium at diagnosis and size of tumour $(P<0.001)$ (Table 3 ). There were also various blood indices (neutrophil, lymphocyte and eosinophil count pretreatment) that were found to be statistically significant between the 2 groups (Table 3 ). Patients who had a malignant cause of CS had a higher pre-operative neutrophil count and a lower pre-operative lymphocyte and eosinophil count when compared to patients having a benign cause. Additionally, there was a statistically significant higher NLR and SII and lower LMR in patients with malignant causes of CS. A significant correlation between a higher cortisol level (baseline and post-ODST), and a lower pre-operative eosinophil and lymphocyte counts and potassium at diagnosis was noted. A positive correlation was present between higher cortisol levels (baseline, post-ODST cortisol and 24-hour urinary cortisol) and pre-operative NLR whilst a negative correlation was observed with pre-operative LMR. More details can be found in Supplemental Table 1. In a sub-analysis on those patients with CS who were cured or in remission after surgery there was a trend towards a lower white cell count, neutrophil count, haemoglobin, SII and NLR, and a higher eosinophil and lymphocyte counts after treatment (Table 4). As expected, there was a strong association between malignant causes of CS and mortality at the end of the study period $(P<0.001)$ (Table 1$)$. 
Table 3

Differences between benign and malignant Cushing's syndrome and between patients who passed away and remained alive - medians (IQR) and p-values

\begin{tabular}{|c|c|c|c|c|c|c|}
\hline & Benign & Malignant & $\begin{array}{l}p- \\
\text { value }\end{array}$ & Alive & Passed Away & $\begin{array}{l}p- \\
\text { value }\end{array}$ \\
\hline Age at Presentation (years) & $52.0(40.0-59.0)$ & $62.0(60.0-66.0)$ & 0.005 & $53.0(40.0-59.0)$ & $62.0(61.0-66.0)$ & 0.003 \\
\hline ODST cortisol (nmol/L) & $380.0(270.3-604.5)$ & $\begin{array}{l}2119.0(1311.5- \\
2574.0)\end{array}$ & $<0.001$ & $380.0(270.3-619.0)$ & $\begin{array}{l}2119.0(1029.5- \\
2574.0)\end{array}$ & $<0.001$ \\
\hline Baseline cortisol (nmol/L) & $579.0(517.3-746.3)$ & $\begin{array}{l}1919.5(1194.8- \\
2146.8)\end{array}$ & $<0.001$ & $578.0(512.0-759.8)$ & $\begin{array}{l}1825.0(855.0- \\
2025.0)\end{array}$ & $<0.001$ \\
\hline $\mathrm{K}^{+}$at diagnosis $(\mathrm{mmol} / \mathrm{L})$ & $4.4(4.1-4.8)$ & $2.1(1.9-3.2)$ & $<0.001$ & $4.6(4.1-4.8)$ & $2.2(2.0-3.2)$ & $<0.001$ \\
\hline Size of tumour $(\mathrm{mm})$ & $25.0(6.0-32.0)$ & $70.0(56.3-97.3)$ & $<0.001$ & $24.0(6.0-35.0)$ & $55.0(29.0-70.0)$ & 0.061 \\
\hline $\begin{array}{l}\text { 24hr urine for cortisol } \\
\text { (nmol/24hrs) }\end{array}$ & $\begin{array}{l}1332.0(811.0 \\
-2430.0)\end{array}$ & $\begin{array}{l}4138.0(2308.0- \\
4485.0)\end{array}$ & 0.008 & $\begin{array}{l}1440.0(933.5 \\
-2440.5)\end{array}$ & $\begin{array}{l}3236.0(918.0- \\
4316.0)\end{array}$ & 0.309 \\
\hline Neutrophil Count pre-Rx $\left(\times 10^{9} / \mathrm{L}\right)$ & $6.6(5.14-8.19)$ & $9.9(6.33-11.08)$ & 0.084 & $6.6(6.0-8.1)$ & $10.3(6.3-10.3)$ & 0.055 \\
\hline Lymphocyte Count pre-Rx (x109/L) & $1.9(1.55-2.41)$ & $1.1(0.87-1.32)$ & 0.001 & $1.9(1.6-2.4)$ & $1.2(1.0-1.4)$ & $<0.001$ \\
\hline Eosinophil Count pre-Rx $\left(\times 10^{9} / \mathrm{L}\right)$ & $0.08(0.02-0.12)$ & $0.01(0.00-0.03)$ & 0.008 & $0.08(0.04-0.12)$ & $0.01(0.00-0.03)$ & 0.003 \\
\hline Platelet Count $\left(\times 10^{9} / \mathrm{L}\right)$ & $288.0(273-331.3)$ & $210.0(184-261)$ & 0.03 & $307.0(273.0-347.0)$ & $198.5(176.5-259.0)$ & 0.001 \\
\hline Neutrophil-to-Lymphocyte Ratio & $3.8(2.6-4.9)$ & $9.1(5.5-14.4)$ & 0.001 & $3.8(2.6-4.8)$ & $8.9(5.6-10.8)$ & $<0.001$ \\
\hline Lymphocyte-to-Monocyte Ratio & $2.5(2.2-2.9)$ & $1.5(1.3-2.0)$ & $<0.001$ & $2.5(2.0-2.9)$ & $1.6(1.4-2.2)$ & 0.007 \\
\hline $\begin{array}{l}\text { Systemic Immune Inflammation } \\
\text { Index }\end{array}$ & $1098(776.6-1607.5)$ & $2013(1726.5-2795.7)$ & 0.005 & $\begin{array}{l}1086.3(772.5- \\
1819.1)\end{array}$ & $\begin{array}{l}1811.7(1344.2- \\
2644.0)\end{array}$ & 0.022 \\
\hline Platelet-Lymphocyte Ratio & $149.7(119.6-202.0)$ & $219.1(198.8-295.1)$ & 0.054 & $149.8(122.6-209.1)$ & $211.8(166.2-239.3)$ & 0.220 \\
\hline
\end{tabular}

Table 4

Differences in blood count indices between pre-treatment and post-treatment levels in those patients who were cured after surgery $(n=21)$ - medians $(I Q R)$ and $p$-values

\begin{tabular}{|llll|}
\hline & Pre-Rx & Post-Rx & $p$-value \\
\hline White Cell Count $\left(\mathrm{x} 10^{9} / \mathrm{L}\right)$ & $9.3(8.26-11.2)$ & $7.4(6.46-8.9)$ & 0.031 \\
\hline Neutrophil Count $\left(\mathrm{x} 10^{9} / \mathrm{L}\right)$ & $6.6(5.30-8.11)$ & $3.9(3.32-6.31)$ & 0.007 \\
\hline Lymphocyte Count $\left(\mathrm{x} 10^{9} / \mathrm{L}\right)$ & $1.9(1.56-2.44)$ & $2.2(1.85-2.85)$ & 0.195 \\
\hline Eosinophil Count $\left(\mathrm{x} 10^{9} / \mathrm{L}\right)$ & $0.07(0.04-0.11)$ & $0.2(0.09-0.25)$ & 0.001 \\
\hline Haemoglobin $(\mathrm{g} / \mathrm{dL})$ & $13.8(12.5-15.3)$ & $12.7(12.1-13.9)$ & 0.066 \\
\hline Neutrophil-to-Lymphocyte Ratio & $3.8(2.6-4.8)$ & $1.8(1.6-2.5)$ & 0.004 \\
\hline Systemic Immune Inflammation Index & $1109.9(623.3-1696.1)$ & $511.9(423.6-886.0)$ & 0.009 \\
\hline
\end{tabular}

\section{Predicting Malignant Disease from Biochemical Parameters}

According to ROC curve analysis, a potassium level of < 3.05 was $75 \%$ sensitive in diagnosing a malignant cause of CS and was $100 \%$ specific (ROC-AUC $0.907,95 \% \mathrm{Cl} 0.78-1.0, P=0.001$ ) giving a positive predictive value (PPV) of $100 \%$ and negative predictive value (NPV) of $89 \%$. A post-ODST cortisol level of > $841 \mathrm{nmol} / \mathrm{L}$ was $100 \%$ sensitive and $91 \%$ specific for diagnosing a malignant cause (ROC-AUC $0.981,95 \% \mathrm{Cl} 0.94-1.0, P<0.001$ ) giving a PPV of $84.5 \%$ and NPV of $100 \%$, whilst a baseline cortisol $>902.5 \mathrm{nmol} / \mathrm{L}$ was $87.5 \%$ sensitive and $92 \%$ specific (ROC-AUC $0.955,95 \% \mathrm{Cl} 0.88-1.0, P<0.001$ ) giving a PPV of $84.3 \%$ and NPV of $93.7 \%$. A $24 \mathrm{hr}$ urinary cortisol $>2513 \mathrm{nmol} / \mathrm{L}$ had a $75 \%$ sensitivity and $84 \%$ specificity $(\mathrm{ROC}-\mathrm{AUC} 0.810,95 \% \mathrm{Cl} 0.63-0.99, P=0.009)$. Furthermore, a lymphocyte count of $<1.77 \times 10^{9} / \mathrm{L}$ was $100 \%$ sensitive and $57.7 \%$ specific (ROC-AUC $0.861,95 \% \mathrm{Cl} 0.72-0.99, P=0.002$ ) giving a PPV of $41.0 \%$ and NPV of $100 \%$, while a NLR ratio $>3.9$ was $100 \%$ sensitive and $57.7 \%$ specific for predicting malignancy $(\mathrm{ROC}-\mathrm{AUC} 0.885,95 \% \mathrm{Cl} 0.76-1.0, P=0.001)$ (Supplemental Figure 1).

\section{Discussion}


Epidemiological studies on all causes of CS are limited, with the majority of the studies including analysis of patients solely with pituitary CD [5, 7, 8, 17-20]. Only three epidemiological studies $[1,3,21]$ have included all causes of CS. Our study is the first epidemiological study that includes patients with all causes of CS in Malta with detailed analysis of all patients.

The incidence of endogenous CS over the 12-year study period was 4.5 cases per million/year, in line with that reported in a study done in Israel [22] and close to that reported in a study done in Vastra Gotaland County in Sweden (3.2 cases per million/year) [3]. However, a lower incidence rate of endogenous CS was reported in other studies [1, 21]. In the study done in New Zealand [1] which included 253 patients with endogenous CS from 4 main endocrinology centres, the reported incidence rate was 1.8 cases per million/year, while in another study done in Denmark [21], where 166 patients with CS were included, the reported incidence rate of CS was 2.3 cases per million/year. Of note, in both studies by Lindholm et al. [21], and Bolland et al. [1], only patients with CS caused by nonmalignant diseases were included, with possible underestimation of the overall incidence rate. Further details are shown in Table 5. 
Table 5

Summary of previous studies analyzing the annual incidence rate of different causes of CS

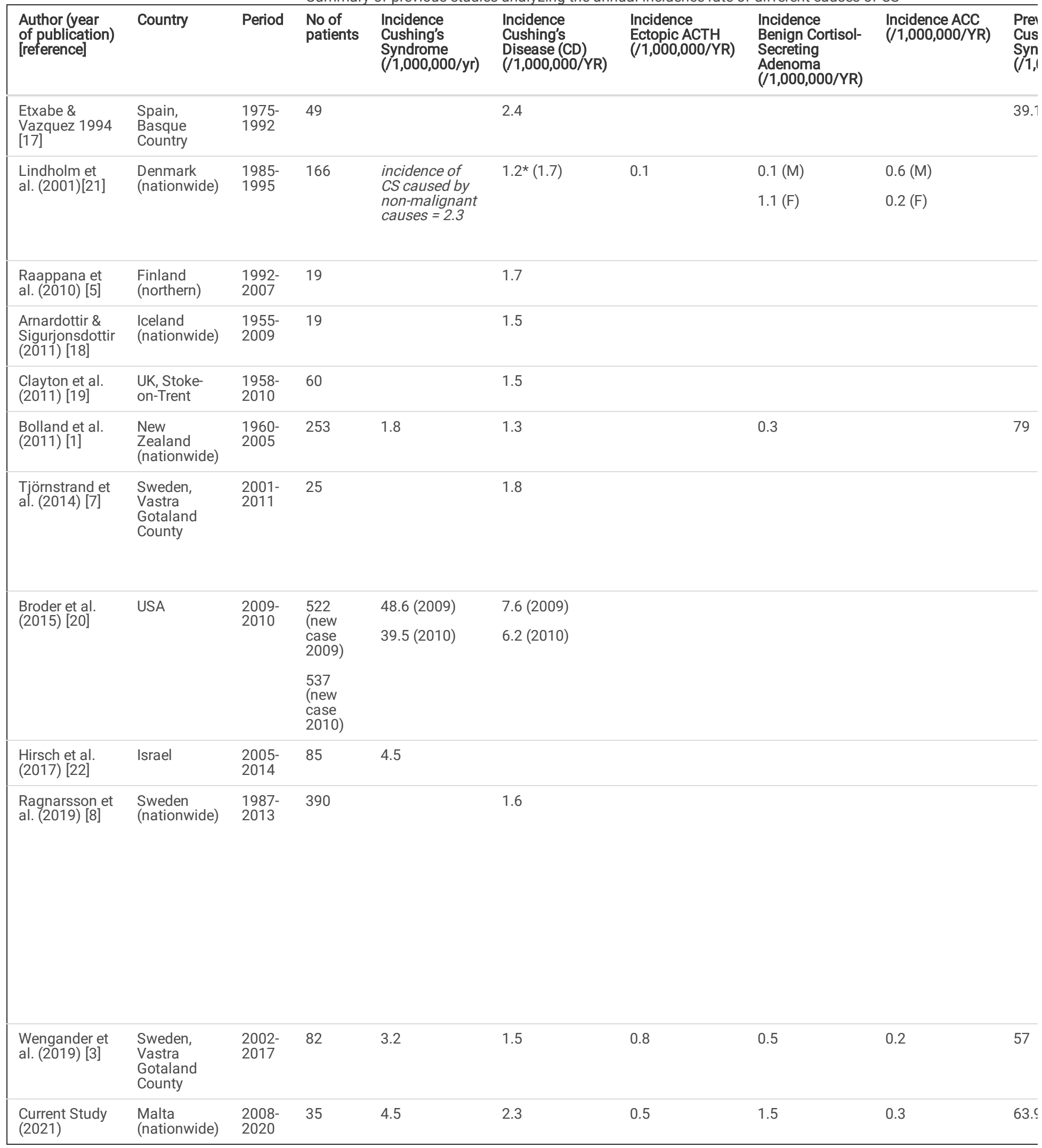

A much higher incidence rate was reported in a study from USA [20], with an incidence rate of 48.6 cases per million/year in 2009 and 39.5 cases per million/year in 2010 for all causes of endogenous CS. The patients included in the study were obtained from information from an insurance database using diagnostic codes for CS. However, the medical records were not reviewed for validation of the diagnosis and this together with other methodological aspects likely led to overestimation of the incidence rate of endogenous CS. 
The incidence of benign cortisol-secreting adrenal adenoma is slightly higher ( 1.5 cases per million/year) than that reported in most studies (0.1-0.5 cases per million/year) but is close to the incidence rate of benign cortisol-secreting adrenal adenomas in females reported by Lindholm et al. [21]. In contrast, we found a considerably higher incidence of $C D$ (2.3 cases per million/year) than that reported in most studies (1.3-1.8 cases per million/year) [1, 3, 5, 7, 8, 18-21]. However, Arnardotir and Sigurionsdottir [18] have also reported a rising incidence from 1.5 to 2.6 per million per year over the last 5 years of their study between 2004 and 2009 whilst Etxabe and Vazquez [17] also found a rising incidence of CD over the years in their study period (from 1.5 to 3.9 per million/year).

The incidence of ectopic ACTH ( 0.5 cases per million/year) is comparable to the recent study done by Wengander et al. [3] ( $0.8 \mathrm{cases}$ per million/year), showing a greater incidence than that previously reported in 2001 by Lindholm et al. (0.1 cases per million/year) [21]. On the contrary, the incidence of ACC ( 0.3 cases per million/year) is consistent to that reported in the previously mentioned studies despite different years of publication [3, 21].

The prevalence of endogenous CS in our study was found to be of 63.9 cases per million. This compares to that of 79 cases per million in New Zealand [1]. However, in a study done by Wengander et al. [3], the estimated prevalence was 57 cases per million. However, it is likely that the prevalence in the latter study was underestimated as patients diagnosed with CS and cured prior to the data collection period, were not included.

\section{Radiological, Biochemical and Blood Count Indices in CS}

During analysis of the different subtypes of patients with endogenous CS, there were statistically significant differences between potassium at diagnosis and size of tumour amongst the different subtypes and between benign and malignant causes of CS (Table $2 \& 3$ ). Patients with malignant CS had a larger tumour size and lower potassium at diagnosis which in turn correlated with a higher cortisol level. Fan et al. [23] similarly showed a correlation between potassium at diagnosis and cortisol in a group of patients with CD. Using ROC curve analysis, we could establish a cut-off value of potassium at diagnosis predicting a malignant cause for CS.

Few studies have investigated the changes in blood components and serum inflammation-based scores in CS [11-13, 24, 25]. Masri-Iraqi et al. [13] looked into the prevalence of leukocytosis in 26 patients with $C D$ and investigated the changes in leukocytes and neutrophils following biochemical cure. Ambrogio et al. [25] studied $80 \mathrm{CD}$ patients and reported on changes in red blood cells (RBCs) and WBC parameters in active Cushing's and after surgical remission, while, Marques et al. [11] compared the pre-operative complete blood counts and various serum inflammatory-based scores in 424 patients with pituitary adenomas, of which 70 patients had CD. The only study, which included patients with all causes of endogenous CS, was done in children by Tatsi et al. [12], and investigated the changes in blood components before and after cure. This makes our study, to our knowledge, the first one to investigate the difference in biochemical and inflammatory parameters in adult patients with all causes of endogenous CS in a population-based epidemiological study and hence respecting the usual prevalence distribution of subtypes.

CS is known to be associated with immune system disruption resulting in polymorphonuclear leukocytosis, lymphopenia, low eosinophils and increased release of various cytokines including tumour necrosis factor alpha, interleukin-1 and interleukin-6, which contribute to a low-grade inflammatory state [10]. In our study, we report similar changes in the blood components in patients with all causes of endogenous CS with neutrophilia, lymphopenia, and low eosinophils. Such changes were noted to be significantly different from those after serum cortisol normalization, clearly exposing the role of cortisol in immune system regulation. Furthermore, we report a positive correlation between the parameters indicating severity of CS, and neutrophil count and NLR, and a negative correlation to lymphocyte, eosinophil count and LMR. Other studies have reported similar findings [11, 13], though these studies studied only patients with CD. The monocyte count was not found to be statistically significant in our cohort. Previous reports showed both a higher monocyte count in patients with CD [11] and a lower monocyte count in patients with CS [10] suggesting a complex relationship between hypercortisolism and monocyte count.

In literature, the effect of CS on platelets is not clearly defined with some studies showing a higher level of platelets [26, 27] whilst others show no significant change in patients with CS [28]. Marques et al. [11] found a higher platelet count in patients with CD when compared to non-functional pituitary adenomas and acromegaly, whilst a lower platelet count was associated with more invasive and refractory disease. In our study, the extent of glucocorticoid excess as defined by cortisol level post ODST, was also found to have a negative association with platelet count. Additionally, patients with malignant causes of CS were found to have a lower platelet count than those with benign causes.

Since all endogenous causes of CS were included in our study, we could report the differences in WBC indices and ratios between the various subtypes and between benign and malignant causes of CS (Table $2 \& 3$ ). Neutrophilia, lymphopenia and low eosinophils were significantly more pronounced in malignant causes of CS and correlated with serum and urine cortisol levels. This further confirms in vivo, the in vitro results reporting a strong correlation between cortisol and the inhibition of lymphocyte proliferation [29]. Moreover, using ROC curve analysis, we attempted to establish useful cut-off values (post-ODST cortisol and 24-hour urinary cortisol) which can help predict malignant causes of CS, which to our knowledge is a novel aspect in the diagnostic workup of CS.

Over the past years, there has been extensive research on the role of different blood components and serum inflammation-based scores on the long-term outcome of different cancers. In a review by Bugada et al. [30], various inflammation-based scores have been mentioned as potential preoperative prognostic markers in cancer patients. An increase in NLR, caused by high neutrophils and low lymphocytes, have been found to be related to the degree of cancer aggressiveness and adverse prognosis in many tumours including lung cancer, breast cancer, thyroid cancer, gastrointestinal cancers, urologic cancers, gynaecological cancers, glioblastoma multiforme and craniopharyngioma [30-35]. Other changes in blood components in malignancy include thrombocytosis, and thus a high PLR, and elevated monocytes which are also associated with poor prognosis in various tumours including gastric cancer, oesophageal, pancreatic, colorectal cancers and urologic cancers [30,33]. However, the role of eosinophil count in malignancy is still uncertain as several studies that have shown both good and poor prognosis with eosinophilia [36, 37].

Different cancers cells from various tissues such as prostate, bladder, breast, kidney and pancreas have been shown in vitro to produce cortisol and suppress CD8+ T-lymphocyte proliferation suggesting a role of cortisol in carcinogenesis [29]. In our study we found that malignant causes of CS had a statistically 
significant higher production of cortisol with a significant greater suppression of lymphocytes and a higher NLR. Extending the in vitro results [29], we can hypothesize on a possible role of cortisol hypersecretion in the tumorigenesis of malignant causes of CS through its effect on immunomodulation. In malignant cancers, polymorphonuclear leukocytosis has been attributed to the increased production of cytokines and growth factors such as granulocytecolony stimulating factors and vascular endothelial growth factor (VEGF) that promote neutrophil proliferation from the bone marrow leading to neutrophilia $[30,38]$. Furthermore, chronic hypercortisolism, promotes the release of polymorphonuclear leukocytes (PMN) from the bone marrow, decreases apoptosis and prolonging their half-life, and decreases the expression of endothelial adhesion molecules on the surface of the neutrophils, thus reducing extravasation from the blood into peripheral tissues [10,13]. The lymphocyte suppression observed in both malignancy and CS, is due to alteration in the CD4+ helper/CH8+ suppressors ratio and apoptosis of mature T-lymphocytes [10,30,39]. Hence, a greater degree of inflammation in malignant and aggressive cancers can possibly stimulate the secretion of a higher level of cortisol to inhibit the tumour-induced immune response, producing more profound changes in serum inflammatory markers, similar to those observed in malignant CS. This process leads to a negative series of events that build on and reinforce each other in the tumorigenesis process.

In our study, a NLR $>3.9$ was $100 \%$ sensitive in predicting malignant CS. In literature, several retrospective studies on different types of tumours, have used various cut-offs, ranging between 2.5 and 5, above which NLR was associated with higher mortality and decreased disease-free survival [30]. Our data thus suggests that the NLR can also be used in patients with CS to predict severity of disease, differentiating between benign and malignant causes, and prognosis.

The relatively small number of patients with CS included, represents a limitation in our study. In Malta, there is one NHS Hospital to which all patients are referred for evaluation, diagnosis and treatment. Hence, we are confident that all patients with suspected endogenous CS in the Maltese Islands were included. While we report a sensible incidence of ACC and ectopic CS, we cannot rule out that some of these patients may have been missed. It is possible that some patients with malignant CS, due to an atypical clinical picture and rapid course of disease, were never referred for an endocrine assessment, with the true incidence rate of both ACC and ectopic CS being somewhat underestimated. This relatively small number of patients may have provided insufficient statistical power to detect significant differences between different subtypes (benign vs malignant causes and pre- vs post-treatment) and certain blood indices. Another limitation is that the study is retrospective and the blood tests were done routinely and not for the study. Additionally, the patients may have had underlying undiagnosed conditions which may have influenced the biochemical and blood count indices.

\section{Conclusion}

Biochemical and blood count indices and serum inflammatory-based scores remarkably differ between benign and malignant causes of endogenous CS and such indices can help in predicting severity of disease and thus prognosis. In our study, an NLR $>3.9$ was $100 \%$ sensitive in predicting malignant CS. Further studies involving larger number of patients with all causes of endogenous CS are needed to further evaluate the role of NLR in CS.

\section{Declarations}

\section{Funding:}

None

\section{Competing interests:}

The authors have no competing interests to declare that are relevant to the content of this article.

\section{Consent to participate:}

Informed consent was obtained from all individual participants included in the study.

\section{Acknowledgements:}

The authors would like to thank Professor S Fava, Dr MJ Cachia, Dr S Vella and Dr AG Abela for their assistance and support in this study and acknowledge all the medical staff and healthcare professionals at Mater Dei Hospital, Malta, who gave invaluable input for this study to be completed.

\section{References}

1. M.J. Bolland, I.M. Holdaway, J.E. Berkeley, S. Lim, W.J. Dransfield, J.V. Conaglen, M.S. Croxson, G.D. Gamble, P.J. Hunt, R.J. Toomath, Mortality and morbidity in Cushing's syndrome in New Zealand. Clin Endocrinol (Oxf). 75, 436-442 (2011).

2. G. Ntali, A. Asimakopoulou, T. Siamatras, J. Komninos, D. Vassiliadi, M. Tzanela, S. Tsagarakis, A.B. Grossman, J.A.H. Wass, N. Karavitaki, Mortality in Cushing's syndrome: systematic analysis of a large series with prolonged follow-up. Eur J Endocrinol. 169, 715-723 (2013).

3. S. Wengander, P. Trimpou, E. Papakokkinou, O. Ragnarsson, The incidence of endogenous Cushing's syndrome in the modern era. Clin Endocrinol (Oxf). 91, 263-270 (2019).

4. A. Fernandez, N. Karavitaki, J.A. Wass, Prevalence of pituitary adenomas: a community-based, cross-sectional study in Banbury (Oxfordshire, UK). Clin Endocrinol (Oxf). 72(3), 377-382 (2010).

5. A. Raappana, J. Koivukangas, T. Ebeling, T. Pirila, Incidence of Pituitary Adenomas in Northern Finland in 1992-2007. J Clin Endocrinol Metab. 95 (9), 4268-4275 (2010). 
6. M. Gruppetta, J. Vassallo, Epidemiology and radiological geometric assessment of pituitary macroadenomas: population-based study. Clin Endocrinol (Oxf). 85(2), 223-231 (2016).

7. A. Tjörnstrand, K. Gunnarsson, M. Evert, E. Holmberg, O. Ragnarsson, T. Rosén, H.F. Nyström, The incidence rate of pituitary adenomas in western Sweden for the period 2001-2011. Eur J Endocrinol. 171, 519-526 (2014).

8. O. Ragnarsson, D.S. Olsson, D. Chantzichristos, E. Papakokkinou, P. Dahlqvist, E. Segerstedt, T. Olsson, M. Petersson, K. Berinder, S. Bensing, C. Höybye, B.E. Engström, P. Burman, L. Bonelli, C. Follin, D. Petranek, E.M Erfurth, J. Wahlberg, B. Ekman, A.K. Åkerman, E. Schwarcz, I.L. Bryngelsson, G. Johannsson, The incidence of Cushing's disease: a nationwide Swedish study. Pituitary 22, 179-186 (2019).

9. M. Gruppetta, C. Mercieca, J. Vassallo, Prevalence and incidence of pituitary adenomas: a population based study in Malta. Pituitary 16(4), 545-553 (2013).

10. V. Hasenmajer, E. Sbardella, F. Sciarra, M. Minnetti, A.M. Isidori, M.A. Venneri, The Immune System in Cushing's Syndrome, Trends Endocrinol Metab. 31(9), 655-669 (2020).

11. P. Marques, F. deVries, O.M. Dekkers, W.R. van Furth, M. Korbonits, N.R. Biermasz, A.M. Pereira, Pre-operative serum inflammation-based scores in patients with pituitary adenomas. Pituitary 24(3), 334-350 (2021).

12. C. Tatsi, R. Boden, N. Sinaii, M. Keil, C. Lyssikatos, E. Belyavskaya, S.D. Rosenzweig, C.A. Stratakis, M.B. Lodish, Decreased Lymphocytes and Increased Risk for Infection are Common in Endogenous Pediatric Cushing Syndrome. Pediatr Res. 83(2), 431-437 (2018).

13. H. Masri-Iraqi, E. Robenshtok, G. Tzvetov, Y. Manistersky, I. Shimon. Elevated white blood cell counts in Cushing's disease: association with hypercortisolism. Pituitary 17(5), 436-440 (2014).

14. National Statistics Office. World Population Day: 11 July 2021. Malta: National Statistics Office, 2021.

15. L.K. Nieman, B. Biller, J.W. Findling, J. Newell-Price, M.O. Savage, P.M. Stewart, V.M. Montori, The diagnosis of Cushing's syndrome: an Endocrine Society Clinical Practice Guideline. J Clin Endocrinol Metab. 93(5), 1526-1540 (2008).

16. O.B. Ahmad, C. Boschi-Pinto, A.D. Lopez, C.J. Murray, R. Lozano, M. Inoue, Age standardization of rates: a new WHO standard. Geneva: World Health Organization (2001).

17. J. Etxabe, J.A. Vazquez, Morbidity and mortality in Cushing's disease: an epidemiological approach. Clin Endocrinol (Oxf). 40(4), 479-484 (1994).

18. S. Arnardóttir, A. Sigurjonsdóttir, The incidence and prevalence of Cushing's disease may be higher than previously thought: results from a retrospective study in Iceland 1955 through 2009. Clin Endocrinol (Oxf). 74(6), 792-793 (2011).

19. R.N. Clayton, D. Raskauskiene, R.C. Ruelen, P.W. Jones, Mortality and Morbidity in Cushing's Disease over 50 Years in Stoke-on-Trent, UK: Audit and MetaAnalysis of Literature. J Clin Endocrinol Metab. 96(3), 632-642 (2011).

20. M.S. Broder, M.P. Neary, E. Chang, D. Cherepanov, W.H. Ludlam, Incidence of Cushing's syndrome and Cushing's disease in commercially-insured patients $<65$ years old in the United States. Pituitary 18(3), 283-289 (2015).

21. J. Lindholm, S. Juul, J.O.L. Jørgensen, J. Astrup, P. Bjerre, U. Feldt-Rasmussen, C. Hagen, J. Jørgensen, M. Kosteljanetz, L. Ø. Kristensen, P. Laurberg, Incidence and late prognosis of Cushing's syndrome: a population-based study. J Clin Endocrinol Metab. 86(1), 117-123 (2001).

22. D. Hirsch, G. Tsvetov, Y. Manisterski, N. Aviran-Barak, V. Nadler, S. Albolm, V. Kopel, Incidence of Cushing's syndrome in patients with significant hypercortisoluria. Eur J Endocrinol. 176, 41-48 (2017).

23. L. Fan, Y. Zhuang, Y. Wang, X. Liu, D. Liu, B. Xiang, M. He, Z. Zhang, Y. Li, Y. Wang, Z. Xiaoming, Y. Hongying, Association of hypokalemia with cortisol and ACTH levels in Cushing's disease. Ann N Y Acad Sci. 1463(1), 60-66 (2019).

24. F.A. De la Balze, J.R. Reifenstein, F. Albright, Differential Blood Counts in Certain adrenal cortical disorders (Cushing's Syndrome, Addison's Disease and Panhypopituitarism). J Clin Endocrinol Metab. 6, 312-9 (1946).

25. A.G. Ambrogio, M. De Martin, P. Ascoli, F. Cavagnini, Gender-dependent changes in haematological parameters in patients with Cushing's disease before and after remission. Eur J Endocrinol. 170(3), 393-400 (2014).

26. T. Sato, R. Hiramatsu, T. Iwaoka, Y. Fujii, T. Shimada, T. Umeda, Changes of platelets, serum lactic dehydrogenase, Y-glutamyltranspeptidase, choline esterase and creatine phosphokinase levels in patients with Cushing's syndrome. Tohoku J Exp Med. 142(2), 195-200 (1984).

27. C. Erem, I. Nuhoglu, M. Yilmaz, M. Kocak, A. Demirel, O. Ucuncu, H.O. Ersoz, Blood coagulation and fibrinolysis in patients with Cushing's syndrome: increased plasminogen activator inhibitor-1, decreased tissue factor pathway inhibitor, and unchanged thrombin-activatable fibrinolysis inhibitor levels. $\mathrm{J}$ Endocrinol Invest. 32(2), 169-174 (2009).

28. V. Deutsch, L. Lerner-Geva, A. Reches, V. Boyko, R. Limor, D. Grisaru, Sustained leukocyte count during rising cortisol level. Acta haematol. 118(2), 73-76 (2007).

29. N. Cirillo, D.J. Morgan, M.C. Pedicillo, A. Celentano, L. Lo Muzio, M.J. McCullough, S.S. Prime. Characterisation of the cancer-associated glucocorticoid system: key role of 11ß-hydroxysteroid dehydrogenase type 2. Br J Cancer 117, 984-993 (2017).

30. D. Bugada, M. Allegri, P. Lavand'Homme, M. De Kock, G. Fanelli, Inflammation-based scores: a new method for patient-targeted strategies and improved perioperative outcome in cancer patients. BioMed Res Int. 2014, 142425 (2014).

31. A.J. Templeton, M.G. McNamara, B. Seruga, F.E. Vera-Badillo, P. Aneja, A. Ocana, R. Leibowitz-Amit, G. Sonpavde, J.J. Knox, B. Tran, I.F. Tannock, E. Amir, Prognostic Role of Neutrophil-to-Lymphocyte Ratio in Solid Tumors: A Systematic Review and Meta-Analysis. J Natl Cancer Inst. 106 (6), dju124 (2014).

32. A. Galvano, M. Peri, A.A. Guarini, M. Castiglia, A. Grassadonia, M. De Tursi, L. Irtelli, S. Rizzo, A. Bertani, V. Gristina, N. Barraco, Analysis of systemic inflammatory biomarkers in neuroendocrine carcinomas of the lung: prognostic and predictive significance of NLR, LDH, ALI, and LIPI score. Ther Adv Med Oncol. 12, 1-11 (2020). 
33. J. Feng, Y. Wang, G. Shan, L. Gao, Clinical and prognostic value of neutrophil-lymphocyte ratio for patients with thyroid cancer: A meta-analysis. Medicine, 99(20), e19686 (2020).

34. G. Luo, C. Liu, H. Cheng, K. Jin, M. Guo, Y. Lu, J. Long, J. Xu, Q. Ni, J. Chen, X. Yu, Neutrophil-lymphocyte ratio predicts survival in pancreatic neuroendocrine tumors. Oncol Lett. 13(4), 2454-2458 (2017).

35. J. Zhang, M. He, Z. Liu, Y. Song, Y. Wang, R. Liang, H. Chen, J. Xu, Impact of neutrophil-lymphocyte ratio on long-term outcome in patients with craniopharyngioma. Medicine, 97(37), e12375 (2018).

36. G. Varricchi, M.R. Galdiero, S. Loffredo, V. Lucarini, G. Marone, F. Mattei, G. Marone, G. Schiavoni, Eosinophils: The unsung heroes in cancer? Oncoimmunology, 7(2), e1393134 (2018).

37. S. Grisaru-Tal, M. Itan, A.D. Klion, A. Munitz, A new dawn for eosinophils in the tumour microenvironment. Nature Reviews Cancer, 20(10), 594-607 (2020).

38. J. Ahmad, N. Grimes, S. Farid, G. Morris-Stiff, Inflammatory response related scoring systems in assessing the prognosis of patients with pancreatic ductal adenocarcinoma: a systematic review. Hepatobiliary \& Pancreat Dis Int. 13(5), 474-481 (2014).

39. I. Ray-Coquard, C. Cropet, M. Van Glabbeke, C. Sebban, A. Le Cesne, I. Judson, O. Tredan, J. Verweij, P. Biron, I. Labidi, J.P. Guastalla, Lymphopenia as a prognostic factor for overall survival in advanced carcinomas, sarcomas, and lymphomas. Cancer Res. 69(13), 5383-5391 (2009).

\section{Supplementary Files}

This is a list of supplementary files associated with this preprint. Click to download.

- EpidemiologyofCSSupplementaryMaterialEndocrine.docx 